\title{
Quantitative microbial risk assessment of Campylobacter jejuni in jerky in Korea
}

\author{
Jimyeong $\mathrm{Ha}^{1,2}$, Heeyoung Lee ${ }^{1,2}$, Sejeong $\mathrm{Kim}^{1,2}$, Jeeyeon Lee ${ }^{1,2}$, Soomin Lee ${ }^{1,2}$, \\ Yukyung Choi ${ }^{1,2}$, Hyemin $\mathrm{Oh}^{1,2}$, and Yohan Yoon ${ }^{1,2, *}$
}

\begin{abstract}
* Corresponding Author: Yohan Yoon Tel: +82-2-2077-7585, Fax: +82-2-710-9479 E-mail: yyoon@sm.ac.kr
\end{abstract}

${ }^{1}$ Department of Food and Nutrition, Sookmyung Women's University, Seoul 04310, Korea 2 Risk Analysis Research Center, Sookmyung Women's University, Seoul 04310, Korea

\section{ORCID}

Jimyeong $\mathrm{Ha}$

https://orcid.org/0000-0001-7973-7926 Heeyoung Lee

https://orcid.org/0000-0001-6115-9179

Sejeong Kim

https://orcid.org/0000-0001-9741-8056 Jeeyeon Lee

https://orcid.org/0000-0002-5885-6835 Soomin Lee

https://orcid.org/0000-0003-1811-7365

Yukyung Choi

https://orcid.org/0000-0002-7994-9862

Hyemin Oh

https://orcid.org/0000-0002-8073-7242

Yohan Yoon

https://orcid.org/0000-0002-4561-6218

Submitted Apr 23, 2018; Revised Jul 19, 2018; Accepted Jul 26, 2018
Objective: The objective of this study was to estimate the risk of Campylobacter jejuni (C. jejuni) infection from various jerky products in Korea.

Methods: For the exposure assessment, the prevalence and predictive models of $C$. jejuni in the jerky and the temperature and time of the distribution and storage were investigated. In addition, the consumption amounts and frequencies of the products were also investigated. The data for $C$. jejuni for the prevalence, distribution temperature, distribution time, consumption amount, and consumption frequency were fitted with the @RISK fitting program to obtain appropriate probabilistic distributions. Subsequently, the dose-response models for Campylobacter were researched in the literature. Eventually, the distributions, predictive model, and dose-response model were used to make a simulation model with @RISK to estimate the risk of $C$. jejuni foodborne illness from the intake of jerky.

Results: Among 275 jerky samples, there were no C. jejuni positive samples, and thus, the initial contamination level was statistically predicted with the RiskUniform distribution [RiskUniform $(-2,0.48)]$. To describe the changes in the C. jejuni cell counts during distribution and storage, the developed predictive models with the Weibull model (primary model) and polynomial model (secondary model) were utilized. The appropriate probabilistic distribution was the BetaGeneral distribution, and it showed that the average jerky consumption was $51.83 \mathrm{~g} / \mathrm{d}$ with a frequency of $0.61 \%$. The developed simulation model from this data series and the dose-response model (Beta Poisson model) showed that the risk of $C$. jejuni foodborne illness per day per person from jerky consumption was $1.56 \times 10^{-12}$.

Conclusion: This result suggests that the risk of $C$. jejuni in jerky could be considered low in Korea.

Keywords: Campylobacter jejuni; Jerky; Quantitative Microbial Risk Assessment

\section{INTRODUCTION}

In recent years, the meats used to produce jerky have expanded to beef, pork, and chicken $[1,2]$. Jerky is a nutritious meat product, and it has a long shelf life, because of its low water activity [3]. However, foodborne outbreaks of microbial diseases have been reported in many countries [4-6]. In recent, Campylobacter foodborne outbreaks have been dramatically increased. This increase may occur by advanced detection methods than the past, rather than actual increase of the outbreak. Campylobacter outbreaks were obviously under-estimated because of inaccurate detection method. Thus, necessity of risk assessment for Campylobacter has been suggested.

Campylobacter species are Gram-negative, microaerophilic bacilli that have shaped like curved rods or spirals $[7,8]$. In the United States, most of the reported Campylobacter infections are caused by Campylobacter jejuni (C. jejuni) [9]. C. jejuni grows well in microaerophilic 
conditions, such as $5 \% \mathrm{O}_{2}, 10 \% \mathrm{CO}_{2}$, and $85 \% \mathrm{~N}_{2}$ environments, and it is sensitive to drying, acidic conditions, and salinity [10]. Additionally, it is a normal intestinal flora of animals, such as cattle, sheep, and poultry $[11,12]$. C. jejuni is a common bacterium that causes acute gastroenteritis worldwide [7]. In general, the symptoms of $C$. jejuni infection are diarrhea, fever, and abdominal cramps. Importantly, following an infection with C. jejuni, Guillain-Barre syndrome, which is an acute demyelinating disease of the peripheral nervous system, is possible [13].

Quantitative microbial risk assessment (QMRA) is widely used as a tool to describe the microbial risk levels of foods [14]. The QMRA consists of hazard identification, exposure assessment, hazard characterization, and risk characterization [15]. In hazard identification, the adverse effects on public health are defined, and the exposure assessment estimates the quantitative hazards in food at the point of consumption [16]. Dose-response models are used in hazard characterization to calculate the probability of foodborne illness [16], and in risk characterization, the risk is calculated from the exposure assessment and hazard characterization data [17]. The QMRA result is used to suggest quantitative criteria of foodborne pathogens, but many countries still do not have quantitative criteria for jerky [18,19]. Also, in Korea there are no quantitative criteria for $C$. jejuni in jerky. Therefore, the objective of this study was to evaluate the risk of $C$. jejuni foodborne illness from various jerkies in Korea.

\section{MATERIALS AND METHODS}

\section{Prevalence level of Campylobacter jejuni}

To evaluate the contamination levels of $C$. jejuni, seasoned ( $\mathrm{n}$ $=125)$ and non-seasoned beef and poultry jerky $(\mathrm{n}=150)$ were purchased from conventional markets, grocery stores, or online shops in Korea. Ten-gram portions of the samples were placed into sterile filter bags (3M, St. Paul, MN, USA), and $40 \mathrm{~mL}$ of Bolton broth (Oxoid Ltd., Basingstoke, UK), supplemented with $5 \%$ laked horse blood, was added and homogenized for $90 \mathrm{~s}$. They were then incubated at $37^{\circ} \mathrm{C}$ for $4 \mathrm{~h}$, followed by incubation at $42^{\circ} \mathrm{C}$ for $44 \mathrm{~h}$. The incubated homogenates were then streaked onto modified charcoal-cefoperazone-deoxycholate agar (mCCDA; Oxoid Ltd., UK) and incubated at $42^{\circ} \mathrm{C}$ for $48 \mathrm{~h}$ under microaerobic conditions (2.5\% to $9.5 \%$ $\mathrm{CO}_{2}, 6.2 \%$ to $13.2 \% \mathrm{O}_{2}$ ) using CampyGen (CampyGen gas generating system, Oxoid Ltd., UK). The presumptive $C$. jejuni colony on the mCCDA was streaked onto two Colombia agar plates (bioMérieux, Marcy-l'Étoile, France), and one plate was incubated under aerobic conditions and the other one was incubated under microaerobic conditions at $42^{\circ} \mathrm{C}$ for $48 \mathrm{~h}$. Further analysis, using PCR to identify C. jejuni, was conducted, when colonies were formed only on the plate that was placed in the microaerobic environment [20]. Additionally, the ho- mogenates were plated onto mCCDA, and the plates were incubated at $42^{\circ} \mathrm{C}$ for $48 \mathrm{~h}$ under microaerobic conditions for quantitative analysis. Presumptive colonies were then counted, and five randomly selected colonies on each plate were analyzed by using of PCR to identify $C$. jejuni. To amplify the constant sequence, primers of $\mathrm{C}-1 \mathrm{~F}$ (5'-CAAATAAAGTTAGAGGTA GAATGT- $3^{\prime}$ ) and C-3R (5'-CCATAAGCACTAGCTAGCTG AT-3') were used [21]. PCR amplification was performed with a $20 \mu \mathrm{L}$ reaction volume using the Fastmix Frenche PCR Premix kit (iNtRON Biotechnology, Seongnam, Korea), $2 \mu \mathrm{L}$ of each primer, $2 \mu \mathrm{L}$ of template DNA, and $14 \mu \mathrm{L}$ of distilled water. The amplification profile was an initial denaturation step at $95^{\circ} \mathrm{C}$ for $15 \mathrm{~min}$, and at $95^{\circ} \mathrm{C}$ for $30 \mathrm{~s}, 58^{\circ} \mathrm{C}$ for $90 \mathrm{~s}$, and $72^{\circ} \mathrm{C}$ for $60 \mathrm{~s}$ for annealing. The annealing step had 25 cycles. Subsequently there was a final extension step at $72^{\circ} \mathrm{C}$ for $7 \mathrm{~min}$. To confirm the amplification of the target sequence, the PCR product was electrophoresed on a $1.5 \%$ agarose gel in $1 \times$ Trisacetate-ethylenediaminetetraacetic acid buffer (Biosesang, Seongnam, Korea) at $100 \mathrm{~V}$ for $20 \mathrm{~min}$. The positive ratio was multiplied by the number of colonies to estimate the $C$. jejuni counts. However, the $C$. jejuni counts were below the detection limit (0.48 log colony-forming unit [CFU]/g), and thus, the $C$. jejuni prevalence data were fit to a uniform distribution [RiskUniform ( $\alpha$ : minimum value, $\beta$ : maximum value)].

\section{Development of a predictive model}

To describe the changes in the $C$. jejuni cell counts during distribution and storage, predictive models were developed. $C$. jejuni NCTC11168 was stored at $-70^{\circ} \mathrm{C}$ in bead stock (AES Chemunex, Combourg, France). One of the beads was streaked on Columbia agar and incubated at $42^{\circ} \mathrm{C}$ for $48 \mathrm{~h}$ under microaerobic conditions. The colonies on the plates were collected by scraping with a loop, and they were again streaked on Columbia agar; the plates were then incubated for $48 \mathrm{~h}$. The colonies were collected in $5 \mathrm{~mL}$ of phosphate-buffered saline (PBS; $\mathrm{pH}$ 7.4; $0.2 \mathrm{~g}$ of $\mathrm{KH}_{2} \mathrm{PO}_{4}, 1.5 \mathrm{~g}$ of $\mathrm{Na}_{2} \mathrm{HPO}_{4} \cdot 7 \mathrm{H}_{2} \mathrm{O}, 8.0 \mathrm{~g}$ of $\mathrm{NaCl}$, and $0.2 \mathrm{~g}$ of $\mathrm{KCl}$ in $1 \mathrm{~L}$ of distilled water). The suspensions were centrifuged at $1,912 \times \mathrm{g}$ for $15 \mathrm{~min}$ at $4^{\circ} \mathrm{C}$ and washed twice with PBS. Then, the supernatants were discarded, and the cell pellets were resuspended in PBS. The optical density measured at $600 \mathrm{~nm}$ of the suspension was adjusted to 2.0 (ca. $5.5 \mathrm{log}$ $\mathrm{CFU} / \mathrm{mL}$ ) for the inoculum. Seasoned or non-seasoned beef jerky was purchased from an online shop in Korea. Ten-gram portions of the samples were placed into a sterile filter bag, and 0.1-mL portions of the inoculum were inoculated on the jerky surface in the sample bag. The samples were rubbed 20 times and packaged aerobically or anaerobically, followed by storage at $10^{\circ} \mathrm{C}, 20^{\circ} \mathrm{C}, 25^{\circ} \mathrm{C}$, and $30^{\circ} \mathrm{C}$. Jerky samples were analyzed at the appropriate time intervals. Then, $30 \mathrm{~mL}$ of $0.1 \%$ buffered peptone water (BPW; Becton, Dickinson and Company, Franklin Lakes, NJ, USA) was added to each sample, and they were homogenized with a BagMixer (Interscience, St. Nom, France) 
for $90 \mathrm{~s}$. The homogenates were serially diluted with BPW. One-tenth of $1 \mathrm{~mL}$ of the diluents was plated on mCCDA for C. jejuni, and the plates were incubated microaerobically. The typical colonies on the plates were manually counted. Then, the Weibull model was fit to the C. jejuni cell count data [22];

$$
\log (N)=\log \left(N_{0}\right)-(\text { time } / \delta)^{\rho}
$$

Where $N_{0}$ is the initial number of cells, $\rho$ is the shape of curve, and $\delta$ is required time for the first decimal reduction. To evaluate the effect of the storage temperature on $\delta$, a polynomial model was used. Additionally, to evaluate the model performance, $C$. jejuni cell count data were collected at $15^{\circ} \mathrm{C}$ and $23^{\circ} \mathrm{C}$ through additional experiments. These observed data were compared to the predicted data from the predictive model. The accuracy between the observed and predicted data was expressed as a value from the root mean square error (RMSE) [23];

$$
\text { RMSE }=\sqrt{\frac{1}{n} \times \sum(\text { observed data }- \text { predicticed data })^{2}}
$$

Where $\mathrm{n}$ represents the number of data points.

\section{Storage temperature and jerky consumption in Korea}

The market storage temperature was collected by personal communication in this research. The transportation temperature from the market to home was collected in a study by Jung [24]. For the daily consumption amount and frequency of jerky consumption, Ministry of Food and Drug Safety [25] data were used. These data were fitted to @RISK version 6.0 (Palisade Corp., Ithaca, NY, USA) to determine the appropriate probabilistic distributions.

\section{Hazard characteristics and risk characterization}

To calculate the probability of foodborne illness, the doseresponse model, developed by Teunis and Havelaar [26] was utilized. To calculate the probability of foodborne illness from C. jejuni through jerky consumption, a simulation model, which was a series of prevalence, contamination levels, storage temperature and time distribution, consumption amount and frequency, and dose-response model, was prepared in the @ RISK program. Eventually, the risk of foodborne illness was calculated through 10,000 iterations of random sampling.

\section{RESULTS AND DISCUSSION}

\section{Prevalence and initial contamination level of Campylobacter jejuni}

The initial contamination level of $C$. jejuni on the seasoned and non-seasoned jerky was investigated, and $C$. jejuni was below the detection limit in all of the samples $(n=275)$. It was as- sumed that the contamination levels were distributed between $0 \mathrm{CFU} / \mathrm{g}$ and below the detection limit, and thus, a uniform distribution [RiskUniform $(-2,0.48)]$ was determined to be appropriate to describe the distribution of the $C$. jejuni contamination levels. The parameters indicate that the $C$. jejuni contamination levels are distributed between -2.0 and 0.48 $\log \mathrm{CFU} / \mathrm{g}$.

\section{Predictive model}

The C. jejuni cell counts decreased dramatically (Figure 1). Especially, the $C$. jejuni cell counts decreased rapidly at higher storage temperatures (Figure 1). Kim et al [27] presented that C. jejuni in beef tartare survived longer at low temperatures, because of $\operatorname{sodB}, k a t A$, and $c l p P$ gene expression by $C$. jejuni. As $C$. jejuni had a longer survival time in the vacuum-packaged seasoned jerky $(\delta=21.855)$ than in the aerobic-packaged seasoned jerky $(\delta=1.352)$ at $10^{\circ} \mathrm{C}$ (data not shown), a primary model was developed for the vacuum-packaged seasoned jerky for the worst-case scenario. The $\mathrm{R}^{2}$ values of the primary model ranged from 0.870 to 0.961 , indicating that the developed primary model was appropriate to describe the kinetic behavior of $C$. jejuni in jerky (Table 1). The $\delta$ values for $C$. jejuni in the vacuum-packaged seasoned jerky decreased from 21.855 to 0.159 , as the temperature increased. To evaluate the effect of the temperature on $\delta$, a secondary model was developed, and the equation was $\delta=(-9.3872)+(315.2666 / \mathrm{T})$ with an $\mathrm{R}^{2}$ of 0.941 (Figure 2, Table 2). Validation of the model performance showed that the RMSE value was 0.447 , and it indicates that the developed models were appropriate to predict the C. jejuni cell counts in jerky during storage and distribution.

\section{Storage time and temperature}

The time and temperature for market storage were collected by personal communication at the market. On average, the jerky was sold within one month and kept at room temperature. Thus, an appropriate probabilistic distribution for the time and temperature in the market was the Pert distribution with parameters $(0,720,2,160)$ and $(0,20,25)$, respectively (Table 2). The transportation time from the market was at a minimum of $0.325 \mathrm{~h}$ and at a maximum of $1.643 \mathrm{~h}$ [24]. In addition, the minimum, mean, and maximum food temperatures during transportation were $10^{\circ} \mathrm{C}, 18^{\circ} \mathrm{C}$, and $25^{\circ} \mathrm{C}$, respectively [24]. The jerky was usually consumed within approximately $120 \mathrm{~h}$ at home and stored for up to $720 \mathrm{~h}$ at room temperature. Thus, the appropriate distribution for the time and temperature at home was the Pert distribution with parameters $(0,120$, $720)$ and $(15,20,25)$, respectively (Table 2$)$.

\section{Jerky consumption in Korea}

As a result of fitting the consumption data with the @RISK program, a BetaGeneral distribution was optimal, and the daily consumption was $51.83 \mathrm{~g}$ on average per person (Figure 

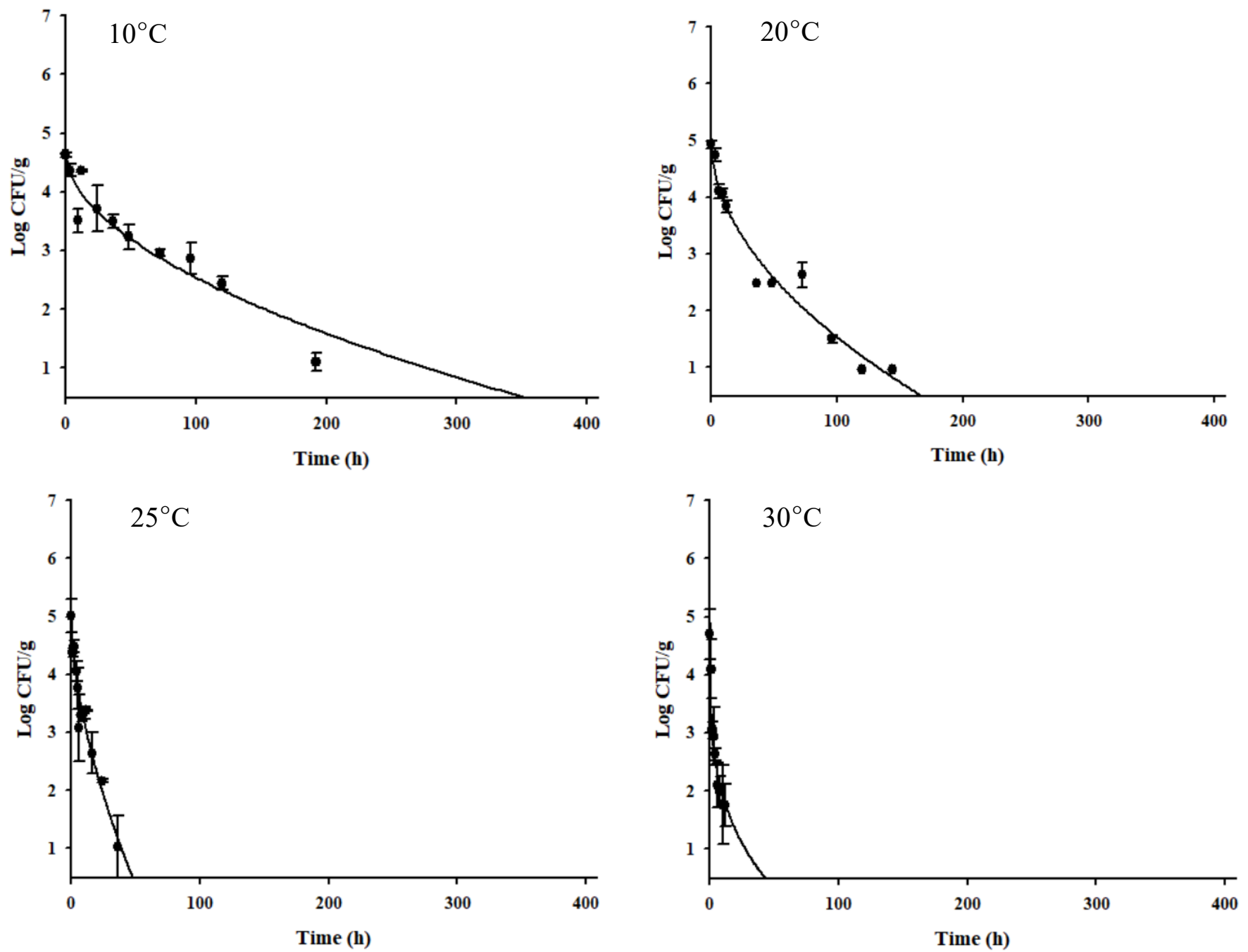

Figure 1. Cell counts of Campylobacter jejuni in seasoned jerky products during vacuum storage at $10^{\circ} \mathrm{C}, 20^{\circ} \mathrm{C}, 25^{\circ} \mathrm{C}$, and $30^{\circ} \mathrm{C}$. Symbol, observed cell counts; line, line fit with the Weibull model [22].

3). According to a survey by MFDS [25], the daily consumption frequency was $0.61 \%$. This means that most people do not consume jerky, and they only consume a small amount compared to the increase in total meat intake.

Dose-response model and risk characterization To estimate the probability of foodborne illness from the consumption of $C$. jejuni cells, the following dose-response model [26] was utilized, because it is the most commonly used and was recently developed.

$$
P_{\text {inf }}(n)=1-\left(1-p_{1}\right)^{n}
$$

Where $p_{1}$ is the probability of consuming Campylobacter cells, which is the value described by the Beta distribution [RiskBeta $(0.145,7.59)], n$ is the number of consumed Campylobacter cells, and $P_{\text {inf }}$ is the probability of infection. To estimate the probability of illness from jerky per person per day, the

Table 1. $\delta$ and $\rho$ calculated by the Weibull model [22] for Campylobacter jejuni in vacuum packaged seasoning jerky during storage at $10^{\circ} \mathrm{C}, 20^{\circ} \mathrm{C}, 25^{\circ} \mathrm{C}$, and $30^{\circ} \mathrm{C}$

\begin{tabular}{lcccc}
\hline \multirow{2}{*}{ Kinetic parameters } & \multicolumn{4}{c}{ Temperature $\left({ }^{\circ} \mathrm{C}\right)$} \\
\cline { 2 - 5 } & 10 & $\mathbf{2 0}$ & $\mathbf{2 5}$ & $\mathbf{3 0}$ \\
\hline$\delta(\mathrm{h})$ & $21.855 \pm 4.773$ & $6.973 \pm 1.853$ & $3.407 \pm 0.774$ & $0.159 \pm 0.036$ \\
$\rho$ & $0.484 \pm 0.078$ & $0.468 \pm 0.051$ & $0.557 \pm 0.060$ & $0.273 \pm 0.002$ \\
$\mathrm{R}^{2}$ & 0.939 & 0.961 & 0.920 & 0.870 \\
\hline
\end{tabular}

$\delta$, required time for the first decimal reduction; $\rho$, shape of curve. 
Table 2. Simulation model and formulas in Excel spreadsheet used to calculate the risk of Campylobacter jejuni in jerky with @RISK

\begin{tabular}{|c|c|c|c|}
\hline Definition & Variable & Formula & Reference \\
\hline \multicolumn{4}{|l|}{ Product } \\
\hline \multicolumn{4}{|l|}{ Pathogens contamination level } \\
\hline Initial contamination level (log CFU/g) & IC & $=$ RiskUniform $(-2,0.48)$ & \\
\hline \multicolumn{4}{|l|}{ Market } \\
\hline \multicolumn{4}{|l|}{ Market storage } \\
\hline Storage time in market $(\mathrm{h})$ & Mark-time $_{\text {st }}$ & $=$ RiskPert $(0,720,2160)$ & Personal communication \\
\hline Storage temperature in market $\left({ }^{\circ} \mathrm{C}\right)$ & Mark-temp $_{\mathrm{st}}$ & $=\operatorname{RiskPert}(0,20,25)$ & Personal communication \\
\hline \multicolumn{4}{|l|}{ Growth } \\
\hline Treatment time for the first decimal reduction & Delta & $=(-9.3872)+\left(315.2666 /\right.$ Mark-temp $\left.p_{s t}\right)$ & This research \\
\hline Shape & $\rho$ & $=$ Fixed 0.445588 & This research \\
\hline Contamination level before transportation (log CFU/g) & $\mathrm{C} 1$ & $=\mathrm{IC}-\left(\text { Mark-time }_{\mathrm{st}} / \mathrm{Delta}\right)^{\mathrm{p}}$ & [31] \\
\hline \multicolumn{4}{|l|}{ Transportation } \\
\hline Transportation time (market to home) (h) & Trans-time & $=\operatorname{Risk} \operatorname{Pert}(0.325,0.984,1.643)$ & [24] \\
\hline Food temperature during transportation $\left({ }^{\circ} \mathrm{C}\right)$ & Trans-temp & $=\operatorname{Risk} \operatorname{Pert}(10,18,25)$ & [24] \\
\hline \multicolumn{4}{|l|}{ Growth } \\
\hline Treatment time for the first decimal reduction & Delta & $=(-9.3872)+(315.2666 /$ Trans-temp $)$ & This research \\
\hline Shape & $\rho$ & $=$ Fixed 0.445588 & This research \\
\hline Contamination level before home (log CFU/g) & $\mathrm{C} 2$ & $=\left(1-(\text { Trans-time } / \text { Delta })^{p}\right.$ & [31] \\
\hline \multicolumn{4}{|l|}{ Home } \\
\hline \multicolumn{4}{|l|}{ Home storage } \\
\hline Storage time until consumption (h) & Home-time $_{\text {st }}$ & $=$ RiskPert $(0,120,720)$ & This research \\
\hline Food temperature until consumption $\left({ }^{\circ} \mathrm{C}\right)$ & Home-temp $_{\text {st }}$ & $=$ RiskPert(15,20,25) & This research \\
\hline \multicolumn{4}{|l|}{ Growth } \\
\hline Treatment time for the first decimal reduction & Delta & $=(-9.3872)+(315.2666 /$ Home-temp $\mathrm{st})$ & This research \\
\hline Shape & $\rho$ & $=$ Fixed 0.445588 & This research \\
\hline Contamination level before consumption (log CFU/g) & $\mathrm{C} 3$ & $=\left(\mathrm{C} 2-\left(\text { Home}- \text { time }_{\mathrm{st}} / \mathrm{Delta}\right)^{\mathrm{p}}\right.$ & [31] \\
\hline \multicolumn{4}{|l|}{ Consumption } \\
\hline Daily consumption average amount (g) & Consump & $=$ RiskBetaGeneral $(1.0586,4.7065,23.985,175.84)$ & [25] \\
\hline Daily consumption frequency $(\%)$ & Confre & Fixed 0.60971 & [25] \\
\hline Daily non consumption frequency (rate) & $C F(0)$ & $=1-0.60971 / 100$ & [25] \\
\hline Daily consumption frequency (rate) & CF(1) & $=0.60971 / 100$ & [25] \\
\hline Distribution for consumption frequency & CF & $=\operatorname{RiskDiscrete}(\{0,1\},\{C F(0), C F(1)\})$ & [25] \\
\hline Daily consumption average amount considered frequency & Amount & $=\operatorname{IF}(\mathrm{CF}=0,0$, Consump $)$ & [25] \\
\hline \multicolumn{4}{|l|}{ Dose-response } \\
\hline Campylobacter amount & $\mathrm{n}$ & $=10^{\mathrm{C} 3} \times$ Amount & \\
\hline Parameter & $\alpha$ & Fixed 0.145 & [26] \\
\hline Parameter & $\beta$ & Fixed 7.59 & [26] \\
\hline Dose-response distribution & P1 & $=\operatorname{RiskBeta}(\alpha, \beta)$ & [26] \\
\hline \multicolumn{4}{|l|}{ Risk } \\
\hline Probability of infection due to ingestion of $n$ & $P_{\text {inf }}(n)$ & $=1-(1-P 1)^{n}$ & {$[28]$} \\
\hline Probability of illness given infection & $P_{\text {ill linf }}$ & Fixed 0.33 & {$[28]$} \\
\hline Probability of illness/person/d & Risk & $=P_{\text {inf }}(n) \times P_{\text {ill } \mid \text { inf }}$ & {$[28]$} \\
\hline
\end{tabular}

CFU, colony-forming unit.

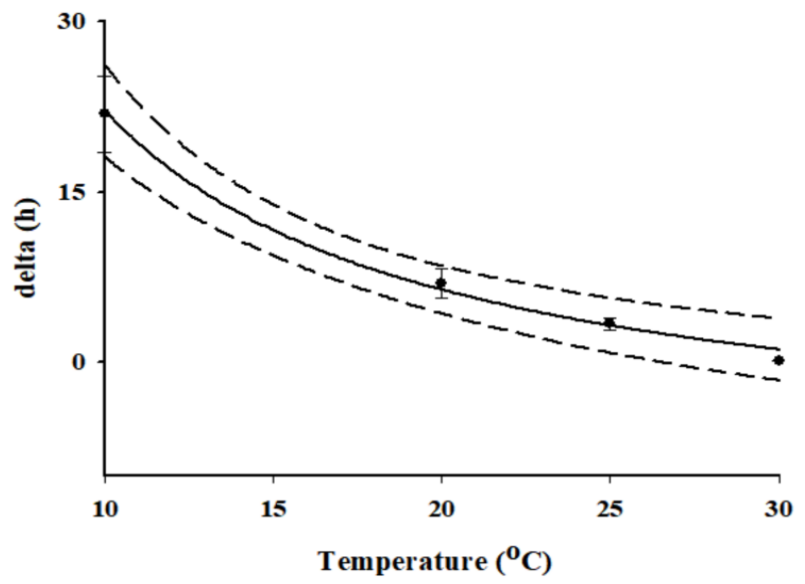

Figure 2. Observed $\delta$ values from the primary model and the fitted lines by a secondary model that describe the effect of temperature on $\delta$ for Campylobacter jejuni in seasoned jerky products. 


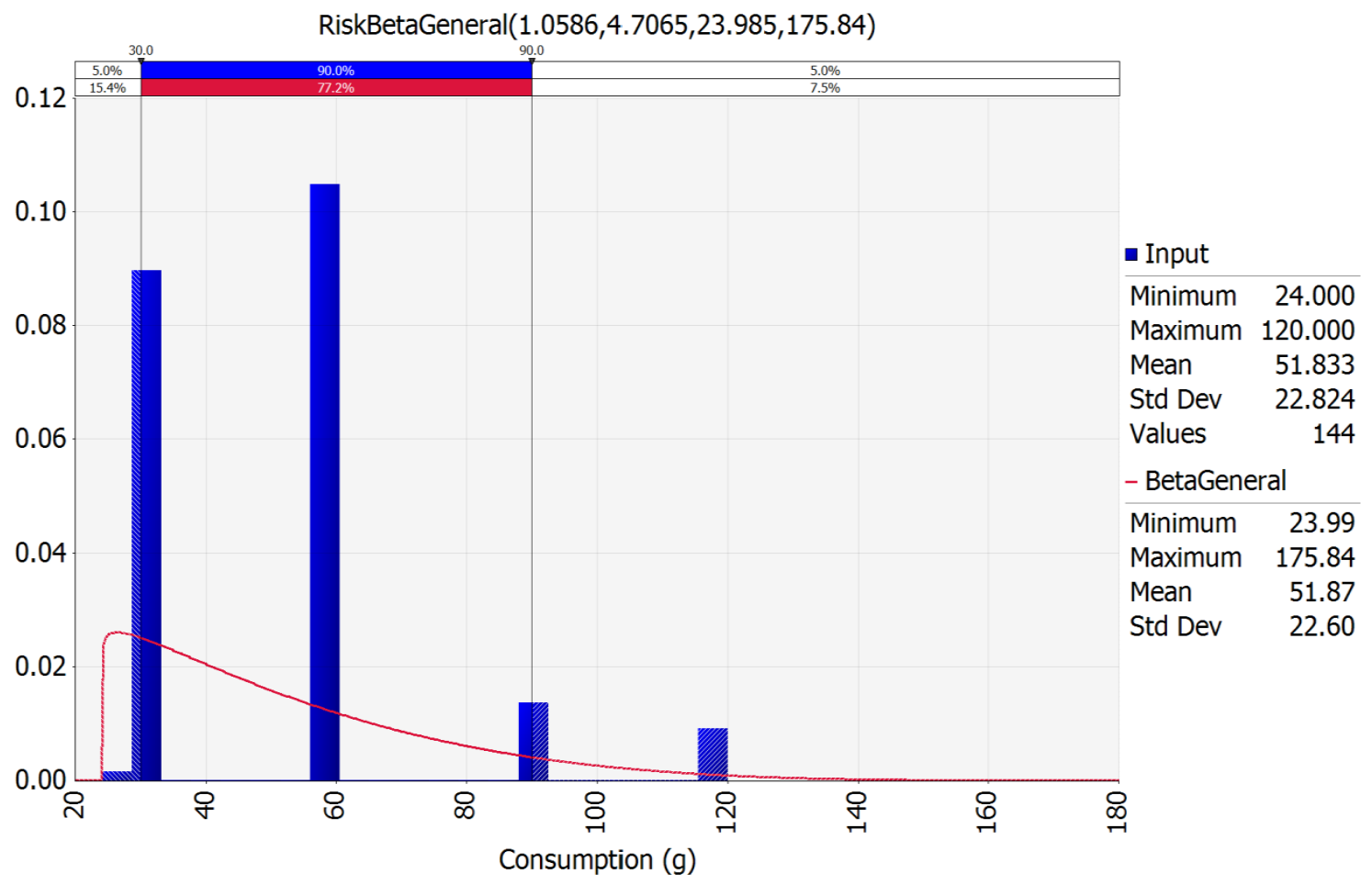

Figure 3. BetaGeneral probabilistic distribution for the jerky intake amount fit with @RISK 6.0.

$P_{\text {inf }}(n)$ values were multiplied by $P_{\text {illinf }}($ fixed 0.33$)$ as follows. $P_{\text {illinf }}$ is the probability of illness from an infection, which has been suggested by Nauta et al [28].
Probability of illness per person per day $=P_{\text {inf }}(n) \times P_{\text {illinf }}$

With all the above data, the simulation model was prepared with a scenario for consumption at home (Figure 4). As the

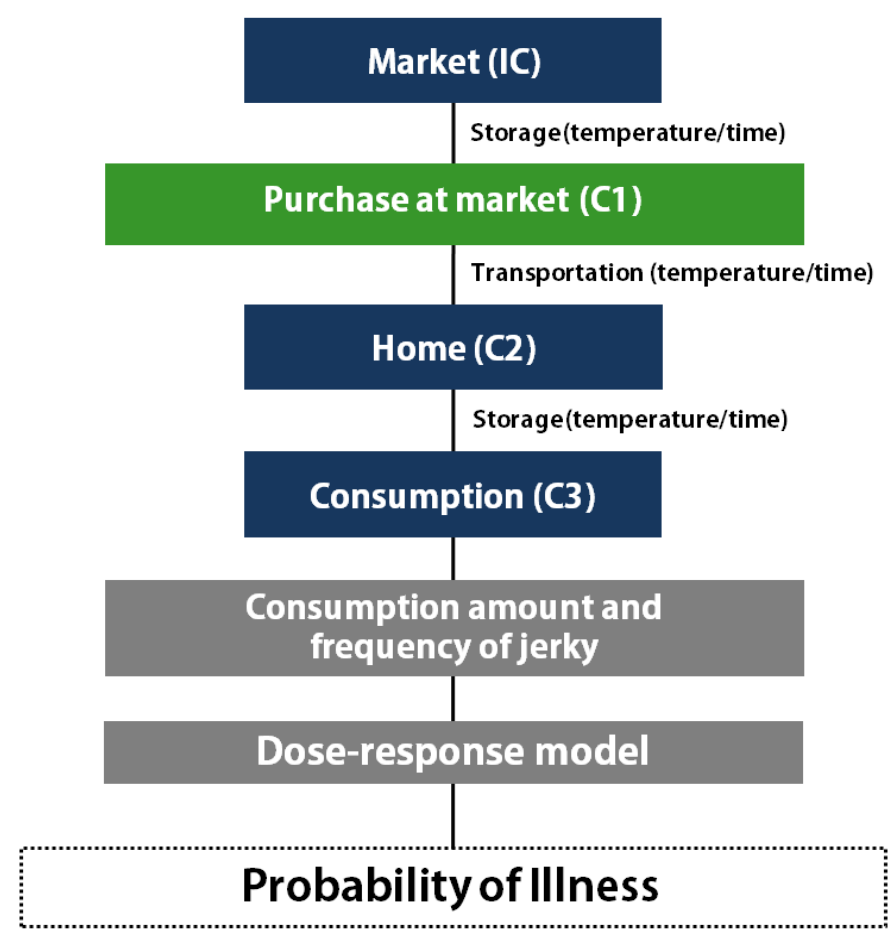

Figure 4. Scheme for the microbial risk assessment of Campylobacter jejuni in jerky. 
Table 3. Probability of foodborne illness of Campylobacter jejuni per person per day and per person per serving by consumption of jerky

\begin{tabular}{lcccccc}
\hline Items & $\mathbf{5 \%}$ & $\mathbf{2 5 \%}$ & $\mathbf{5 0 \%}$ & $\mathbf{9 5 \%}$ & $\mathbf{9 9 \%}$ & Mean \\
\hline Probability of illness/person/d & 0 & 0 & 0 & 0 & 0 & $1.56 \times 10^{-12}$ \\
Probability of illness/person/serving & 0 & 0 & 0 & $1.30 \times 10^{-10}$ & $1.11 \times 10^{-8}$ & $1.76 \times 10^{-8}$ \\
\hline
\end{tabular}

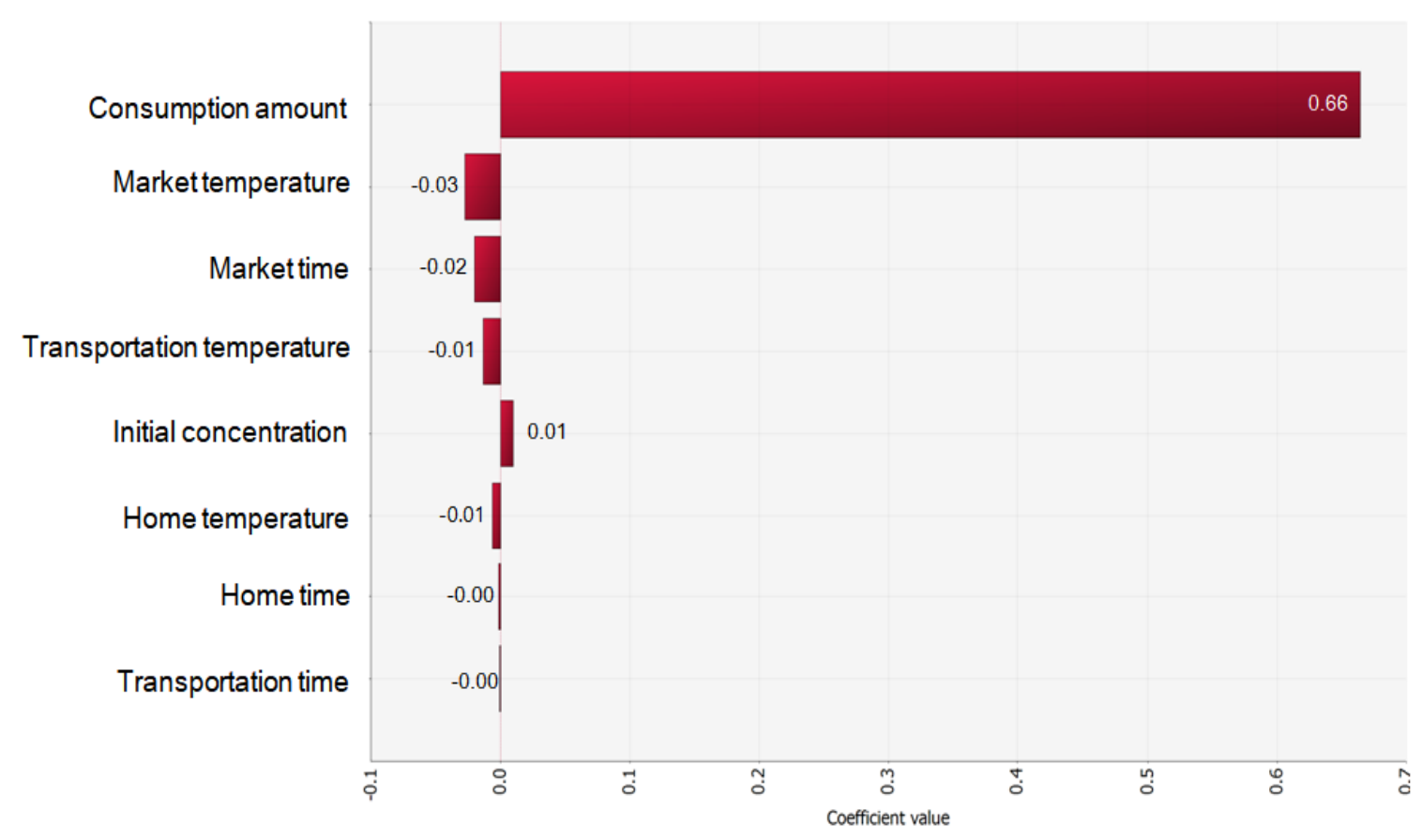

Figure 5. The correlation coefficient values of the risk factors that affect the probability of illness caused by jerky consumption per person per day.

consumption frequency was not high, the risk was assessed by either including or excluding the consumption frequency. The risk estimated with the frequency indicates the overall risk in Korea, and the risk estimated without the frequency indicates the risk for a person who eats jerky. The probability of $C$. jejuni foodborne illness from jerky consumption per person per day was $1.56 \times 10^{-12}$ with the consumption frequency, and $1.76 \times 10^{-8}$ without the consumption frequency, showing the probability of illness per person per serving (Table 3). These results indicate that the risk of $C$. jejuni foodborne illness from jerky intake can be considered low in Korea. This result is similar to the risk of Campylobacter spp. infection from ham, and much lower than the risk from raw beef offal $[29,30]$. As a result of the sensitivity analysis, the most influential risk factor was the consumption amount. Additionally, the market temperature, time, transportation temperature, and risk were negative correlations (Figure 5), indicating that the $C$. jejuni counts decrease during distribution.

In conclusion, the quantitative risk assessment suggests that the risk of C. jejuni infection from the intake of jerky is low in Korea. Even if the jerky is contaminated with $C$. jejuni at a factory, the pathogen is destroyed during the distribution and storage.

\section{CONFLICT OF INTEREST}

We certify that there is no conflict of interest with any financial organization regarding the material discussed in the manuscript.

\section{ACKNOWLEDGMENTS}

This research was supported by a grant (16162MFDS584) from Ministry of Food and Drug Safety in 2016.

\section{REFERENCES}

1. Pegg RB, Amarowicz R, Code WE. Nutritional characteristics of emu (Dromaius novaehollandiae) meat and its value-added products. Food Chem 2006;97:193-202.

2. Han DJ, Jeong JY, Choi JH, et al. Effects of drying conditions on quality properties of pork jerky. Korean J Food Sci Anim Resour 2007;27:29-34.

3. Calicioglu M, Sofos JN, Kendall PA. Influence of marinades on survival during storage of acid-adapted and nonadapted Listeria monocytogenes inoculated post-drying on beef jerky. Int J Food Microbiol 2003;86:283-92. 
4. Keene WE, Sazie E, Kok J, et al. An outbreak of Escherichia coli 0157: H7 infections traced to jerky made from deer meat. JAMA 1997;277:1229-31.

5. Eidson M, Sewell CM, Graves G, Olson R. Beef jerky gastroenteritis outbreaks. J Environ Health 2000;62:9-13.

6. Tauxe RV. Emerging foodborne diseases: an evolving public health challenge. Emerg Infect Dis 1997;3:425-34.

7. Acheson D, Allos BM. Campylobacter jejuni infections: update on emerging issues and trends. Clin Infect Dis 2001;32:12016.

8. Allos BM, Blaser MJ. Campylobacter jejuni and the expanding spectrum of related infections. Clin Infect Dis 1995;20:1092-9.

9. Friedman CR, Neimann J, Wegener HC, Tauxe RV. Epidemiology of Campylobacter jejuni infections in the United States and other industrialized nations. 2nd ed. Washington, DC, USA: ASM International Press; 2000.

10. Altekruse SF, Stern NJ, Fields PI, Swerdlow DL. Campylobacter jejuni-an emerging foodborne pathogen. Emerg Infect Dis 1999;5:28-35.

11. Fricker CR, Park RWA. A two-year study of the distribution of 'thermophilic' campylobacters in human, environmental and food samples from the Reading area with particular reference to toxin production and heat-stable serotype. J Appl Bacteriol 1989;66:477-90.

12. Penner JL. The genus Campylobacter: a decade of progress. Clin Microbiol Rev 1988;1:157-72.

13. Allos BM. Association between Campylobacter infection and Guillain-Barré syndrome. J Infect Dis 1997;176(Suppl 2):S1258.

14. Nauta MJ. Separation of uncertainty and variability in quantitative microbial risk assessment models. Int J Food Microbiol 2000;57:9-18.

15. Codex. Principles and guidelines for the conduct of microbiological risk assessment. CAC/GL 30. 1999. [cited 2018 March 15]. Available from: www.fao.org/docrep/004/y1579e/ y1579e05.htm

16. Duffy G, Cummins E, Nally P, O’Brien S, Butler F. A review of quantitative microbial risk assessment in the management of Escherichia coli O157:H7 on beef. Meat Sci 2006;74:76-88.

17. Notermans S, Teunis P. Quantitative risk analysis and the production of microbiologically safe food: an introduction. Int J Food Microbiol 1996;30:3-7.

18. CFS (Centre for Food Safety), Microbiological guidelines for food. Queensway, Hong Kong: Centre for Food Safety; 2014.

19.FSAI (Food Safety Authority of Ireland), Guidelines for the interpretation of results of microbiological testing of ready-toeat foods placed on the market (Revision 2). Dublin, Ireland: Food Safety Authority of Ireland; 2016.

20. Yamazaki-Matsune W, Taguchi M, Seto K, et al. Development of a multiplex PCR assay for identification of Campylobacter coli, Campylobacter fetus, Campylobacter hyointestinalis subsp. hyointestinalis, Campylobacter jejuni, Campylobacter lari and Campylobacter upsaliensis. J Med Microbiol 2007;56:1467-73.

21. Wang RF, Slavik MF, Cao WW. A rapid PCR method for direct detection of low numbers of Campylobacter jejuni. J Rapid Methods Autom Microbiol 1992;1:101-8.

22.van Boekel MA. On the use of the Weibull model to describe thermal inactivation of microbial vegetative cells. Int J Food Microbiol 2002;74:139-59.

23. Baranyi J, Ross T, McMeekin TA, Rogerts TA. Effects of parameteriza $\neg$ tion on the performance of empirical models used in 'predictive microbiology'. Food Microbiol 1996;13:83-91.

24. Jung H. Consumer survey and hazard analysis for the improvement of food hygiene and safety in purchase. [master's thesis]. Seoul, Korea: Korea University; 2011.

25.MFDS (Ministry of Food and Drug Safety), Microbial Risk Assessment for Campylobacter spp. in Meat and Processed Meat Products; 2016. Report No.: 1475009182.

26. Teunis $P$, Havelaar A. The beta Poisson dose-response model is not a single-hit model. Risk Anal 2000;20:513-20.

27. Kim S, Jeong J, Lee H, et al. Kinetic behavior of Campylobacter jejuni in beef tartare at cold temperatures and transcriptomes related to its survival. J Food Protect 2017;80:2127-31.

28. Nauta MJ, Jacobs-Reitsma WF, Havelaar AH. A risk assessment model for Campylobacter in broiler meat. Risk Anal 2007; 27:845-61.

29. Lee J, Ha J, Kim S, et al. Quantitative microbial risk assessment for Campylobacter spp. on ham in Korea. Korean J Food Sci Anim Resour 2015;35:674-82.

30. Jeong J, Lee J, Lee H, et al. Quantitative microbial risk assessment for Campylobacter foodborne illness in raw beef offal consumption in South Korea. J Food Protect 2017;80:609-18.

31. Mafart P, Couvert O, Gailard S, Leguérinel I. On calculating sterility in thermal preservation methods: application of the Weibull frequency distribution model. Int J Food Microbiol 2002;72:107-13. 